\title{
Analysis of differentially expressed genes in early- and late-stage APPsw-transgenic and normal mice using cDNA microarray
}

\author{
SEUNG W. JEE ${ }^{1}$, JUNG S.CHO ${ }^{1}$, CHUEL K. KIM ${ }^{1}$, DAE Y. HWANG ${ }^{1}$, SUN B. SHIM ${ }^{1}$, SU H. LEE ${ }^{1}$, JI S. SIN ${ }^{1}$, \\ YANG S. KIM ${ }^{2}$, JIN H. PARK ${ }^{1}$, SE H. LEE ${ }^{1}$, SOO Y. CHOI ${ }^{3}$ and YONG K. KIM ${ }^{1}$ \\ ${ }^{1}$ Team of Laboratory Animal Resources, ${ }^{3}$ National Institute of Toxicological Research, Korea FDA, Seoul 122-704; \\ ${ }^{2}$ Bioinformatics Division, ISTECH Inc., Department of Oriental Physiology, Kyunghee University, Seoul 130-701, Korea
}

Received July 24, 2006; Accepted September 28, 2006

\begin{abstract}
The complexity of Alzheimer's disease (AD) has made it difficult to examine its underlying mechanism. A gene microarray offers a solution to the complexity through a parallel analysis of most of the genes expressed in the brains from AD-transgenic mice. In our previous study, a total of 52 differentially expressed genes were identified in 18-monthold APPsw-transgenic mice compared to age-matched normal mice. We extended our work to better understand the relevant gene profiles from both early- and late-stage transgenic and normal mice. To accomplish this, cDNA microarray was used with the large-scale screening of the brain mRNA from transgenic and normal mice of 1 and 18 months of age. We identified a total of 48 genes, 6 upregulated and 42 down-regulated, differentially expressed with a significant degree of induction and reduction in the brains from moderate 18 -month-old transgenic mice compared to 1-month-old transgenic mice. In parallel, a total of 40 differentially expressed genes, 6 up-regulated and 34 down-regulated, were also found in the brains from moderate 18-month-old normal mice compared to 1-month-old normal mice. Thus, differentially expressed genes upon APPsw overexpression and the aging process are useful targets through which investigators can choose genes of particular interest. In the future, it will be necessary to study the function of differentially expressed genes, which are targets for developing drugs, using pharmacoproteomics.
\end{abstract}

\section{Introduction}

The massive accumulation of abnormal fibrous amyloid $\beta$ protein $(A B)$ in the brain is the most common cause of Alzheimer's disease (AD), which is accompanied by memory

Correspondence to: Dr Yong K. Kim, Team of Laboratory Animal Resources, National Institute of Toxicological Research, Korea FDA, 5 Nokbundong Eunpyungku, Seoul 122-704, Korea

E-mail: kimyongkyu@hanmail.net

Key words: Alzheimer's disease, cDNA microarray, transgenic, APPsw and cognitive impairment. $A B$ is deposited as extracellular senile plaques, composed of the 39 to 43 amino acid-long peptides derived from the amyloid precursor protein (APP) by cleavage with $\beta$ - and $\gamma$-secretase. An $\alpha$-secretase cleaves the middle of the $A B$ region releasing a secreted ectodomain containing the first 16 amino acids of the $A \beta(\operatorname{sAPP} \alpha)$. A $\beta$ secretase [ $\beta$-site APP cleaving enzyme (BACE)] cleaves between Met 671 and Asp672, producing a membrane-bound $\mathrm{COOH}$-terminal fragment of the BAPP (sAPPB), which is the substrate of $\gamma$-secretase (1). The sAPP $\beta$ can be transported back to the cell surface where the final $\gamma$ secretase cleaves the end of the $\mathrm{SAPP} \beta$, resulting in the $A \beta$ release with a secreted ectodomain (2). This $A \beta$ is a key event in the pathogenesis of AD. Thus, AD is a complex, progressive disorder resulting in increased cognitive impairment.

With the understanding that AD is hampered by its complexity, there currently exists new genomic technology, such as complementary DNA (cDNA) microarray. cDNA microarrray is one potential technology that can be used to explore the interactions between gene expression and disease. This approach is characterized by high-density arrays of cDNA sequences, bound to a structural support such as glass. The genome-wide expression profiling of thousands of genes provides rich data on genes that best characterize the diseased state. One of the first microarrays showed about 3 times as many known down-regulated genes in comparison to amplified RNA from normal and tangle-bearing neurons of AD (3). There were also several changes in genes under neurotransmitter regulation observed in the superior temporal gyrus from cDNA microarray analysis (4). Furthermore, the down-regulation of several gene transcript families, including genes for cytoskeletal mobility and protein and fatty acid metabolisms were observed using cDNA microarray (4). In the Alzheimer's disease model of C.elegans, 67 up-regulated and 240 down-regulated genes were identified using cDNA microarray (5). It has also been reported that the amyloidcontaining region of the transgenic brain, co-expressing amyloid precursor protein $(A P P)$ and presenilin-1, had high levels of inflammation-associated gene expression, although the most intriguing region of the gene expression profile was selectively decreased (6).

We previously produced transgenic mice expressing neuron-specific enolase (NSE) promoter-controlled APPSw 
(7). It was demonstrated that cognitive deficits along with Aß-42 depositions were shown at 12 months of age in transgenic mice. These mice provide an important resource in gaining insight into the potentially overexpressed effect of $A P P s w$ on the modulation of genes for $\mathrm{AD}$, which is central to understanding the complexity of $\mathrm{AD}$. Moreover, a total of 52 differentially expressed genes, which are associative ADrelated phenotypes, were found in NSE/APPsw-transgenic mouse brains (18 months old) compared to non-transgenic brains of identical age using cDNA microarray (8). However, the differences in gene profiles from early- and late-stage transgenic and normal mice have not been characterized

In this study, the previous study was extended in order to elucidate the relevant gene profiles using cDNA microarray technique in a large-scale screening of brain mRNA from 1and 18-month-old APPsw-transgenic and normal mice. Here, 18-month-old transgenic mice were chosen as they may have the $A ß-42$ plaques and neuronal loss corresponding to $\mathrm{AD}$ pathology, and in addition, there may be neuronal loss in normal aging mice. This study identified 48 and 40 differentially expressed genes with a significant degree of induction and reduction in brains exhibiting moderate AD and aged brains (18 months of age) compared to those in early-stage transgenic and normal mice (1 month of age).

\section{Materials and methods}

Mice. Transgenic lines, expressing the NSE/APPSw fusion gene, were established by backcrossing the founder mice with the parental strain of C57BL/6 mice (7). Transgenic and normal mice were handled in accredited Korea FDA animal facilities in accordance with AAALAC International Animal Care policy (Accredited Unit-Korea Food and Drug Administration, unit no. 000996). Mice were housed in cages under a strict light cycle (lights on at 06:00 and off at 18:00). In addition, all mice were given a standard irradiated chow diet (Purina Mills, Inc) ad libitum, and maintained in a specific pathogen-free state.

RNA isolation. The brains were used for isolating total RNA using Trizol ${ }^{\mathrm{TM}}$ reagent (Invitrogen, Carlsbad, CA) and purified using an RNeasy Total RNA Isolation kit (Qiagen, Valencia, CA) according to the manufacturer's instructions. The RNA quantity and quality were checked by a spectrophotometer, and the integrity was assessed on a denaturing $0.8 \%$ agarose gel. Since the brain environment is in an acidic condition $(<\mathrm{pH} 6.5)$ with a prolonged agonal phase, the purified RNA message was checked on an agarose gel to assess degradation prior to the synthesis of cDNA (9). There was no degradation of the RNA message profile from the brains.

cDNA microarray. The profiling of gene expression was analyzed with a Tween-Chip Mouse-7.4K (Digital Genomics, Seoul) consisting of 7616 mouse cDNA clones. For the synthesis of proof cDNA, RNA was used to generate Cy3and Cy5-labeled cDNA, and probe cDNA microarray slides as described (10). The GeneScript II (Gibco BRL, Rockville,
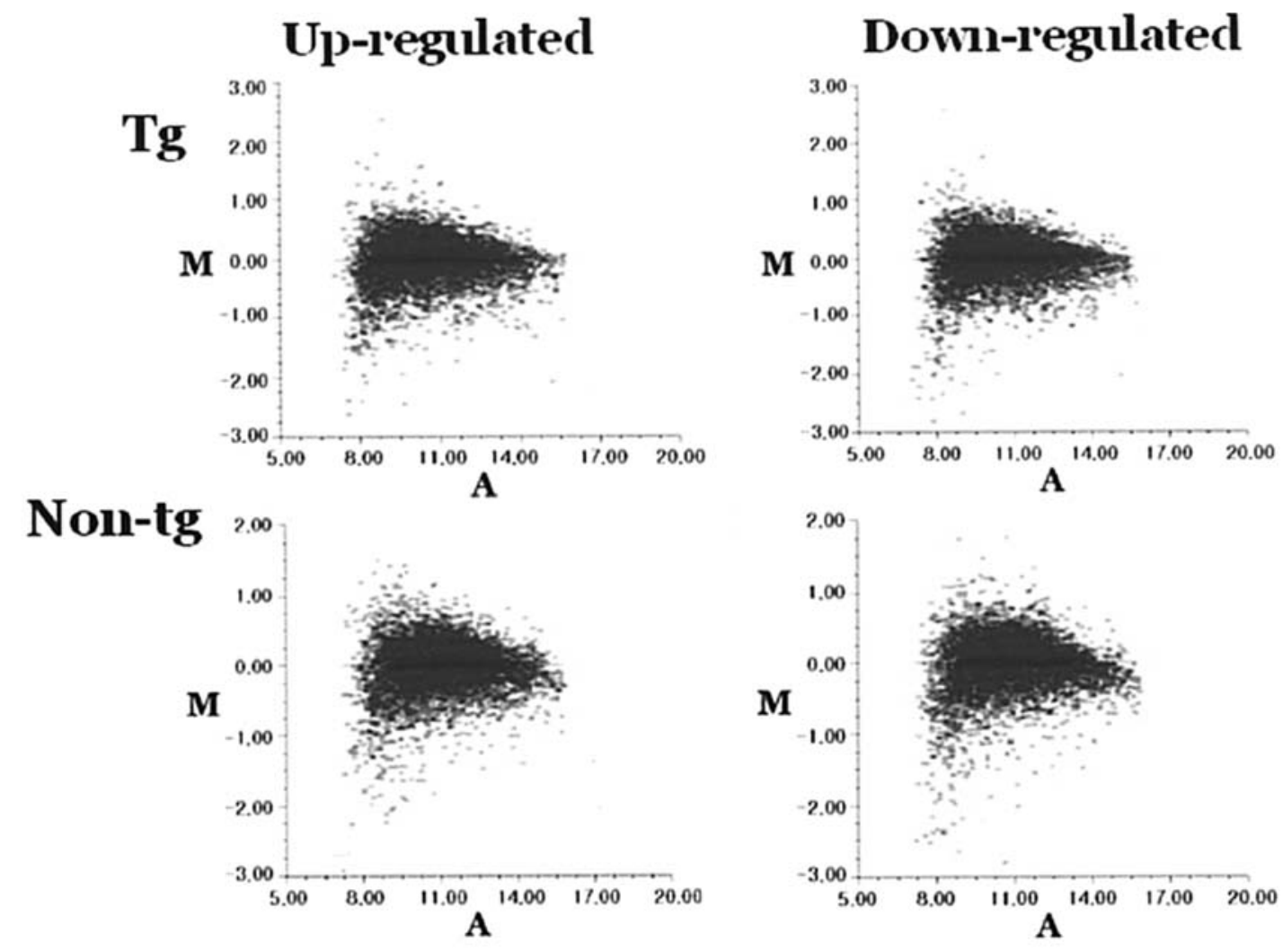

Figure 1. MA plots of cDNA microarray hybridization. Gene expression signal of mouse brains. MA plots were used to represent $R, G$ data, where $\mathrm{M}=\log 2 \mathrm{R} / \mathrm{G}$, and $\mathrm{A}=\log 2(\mathrm{RxG})$. M, expression ratio; $\mathrm{A}$, signal intensity; $\mathrm{G}$, stronger 1-month-old mouse sample hybridization (Cy3); R, stronger 18-monthold mouse sample hybridization (Cy5). One- and 18-month-old transgenic (Tg) and non-transgenic mice (Non-tg) are indicated (up-regulated genes and down-regulated genes). 
Table I. Gene profiles in transgenic mice.

A. Down-regulated genes.

\begin{tabular}{lcc}
\hline Gene symbol & Description & $\begin{array}{c}\text { GenBank Fold change } \\
\text { accession no. }\end{array}$ \\
\hline
\end{tabular}

Cell growth and maintenance

Abca2

Chrna4

Col1a1

Colla2

Col3a1

Gsn

Hao3

Krt1-10

Mg29

$\mathrm{Mpz}$

Myo7a

Nup160

Slc23a1

Cell death

Cradd

Apoptosis

Dock1

Cell cycle

Tacc3

Transcription

En2

Gata3

Harp

Ncoa6

Ppargcla

Stat5a

Immune response

Adn

Chi313

Daf1

Response to stress

Eif2ak3

Ucp3

Signal transduction

Adrb2

Adrb3

Car8

Gabra6

Gna13

Il10ra

Map3k6

Pcp2

Ppp1r1a

Psen2

Rai3

Rgs12

Spnb2

Tnf

Tyk2
ATP-binding cassette, sub-family A (ABC1), member 2

cholinergic receptor, nicotinic, $\alpha$ polypeptide 4

procollagen, type I, $\alpha 1$

procollagen, type I, $\alpha 2$

procollagen, type III, $\alpha 1$

gelsolin

hydroxyacid oxidase (glycolate oxidase) 3

keratin complex 1 , acidic, gene 10

mitsugumin 29

myelin protein zero

myosin VIIa

nucleoporin 160

solute carrier family 23 (nucleobase transporters), member 1

CASP2 and RIPK1 domain containing adaptor with death domain

dedicator of cyto-kinesis 1

AI429136

transforming, acidic coiled-coil containing protein 3

engrailed 2

AI844870

AI428208

AI452087

AA517662

AF049330

AA763337

M11768

AI505981

AI120685

AI427929

AF053352

uncoupling protein 3 , mitochondrial

adrenergic receptor, $B 2$

BC032883

AF193027

AI838156

AI839865

AI426467

AI173487

AI155236

AI843793

AI325468

AI851854

AA096667

AI450971

AI448706

M13049

AI452085

$-2.14$

$-3.17$

$-2.57$

$-2.54$

$-2.67$

$-3.09$

$-2.73$

$-2.11$

$-2.91$

$-3.38$

$-3.16$

$-4.42$

$-2.48$

$-2.80$

$-2.02$

$-2.34$

$-2.18$

$-4.21$

$-5.20$

$-2.47$

$-2.31$

$-2.14$

$-3.33$

$-2.23$

$-3.82$

$-3.23$

$-3.14$

$-2.35$

$-2.08$

$-2.77$

$-2.57$

$-3.40$

$-4.59$

$-2.04$

$-2.77$

$-2.94$

$-2.71$

$-3.50$

$-3.94$

$-2.12$

$-2.13$

tumor necrosis factor

tyrosine kinase 2 
Table I. Continued.

B. Up-regulated genes.

\begin{tabular}{|c|c|c|c|}
\hline Gene symbol & Description & $\begin{array}{c}\text { GenBank } \\
\text { accession no. }\end{array}$ & Fold change \\
\hline \multicolumn{4}{|c|}{ Cell growth and maintenance } \\
\hline Gstk1 & glutathione S-transferase $\kappa 1$ & AI323948 & 2.10 \\
\hline Stxbp3 & syntaxin binding protein 3 & AI528529 & 2.25 \\
\hline \multicolumn{4}{|l|}{ Apoptosis } \\
\hline Pglyrp1 & peptidoglycan recognition protein 1 & AI507116 & 2.41 \\
\hline Trp53inp1 & transformation related protein 53 inducible nuclear protein 1 & AI835817 & 2.39 \\
\hline \multicolumn{4}{|l|}{ Cell cycle } \\
\hline Nbn & Nibrin & AI850789 & 2.39 \\
\hline \multicolumn{4}{|c|}{ Immune response } \\
\hline Orm1 & Orosomucoid 1 & AI117779 & 2.65 \\
\hline
\end{tabular}

MD) in combination with an oligo dT18 primer (Ambion, Austin, TX) were used to synthesize labeled cDNA from total RNA. After removing the unincorporated fluorescent nucleotide, the $\mathrm{Cy} 3$ - and $\mathrm{Cy}$-5-labeled cDNA proofs were mixed together and hybridized overnight at $65^{\circ} \mathrm{C}$ on microarray slides. After hybridization, the solution was removed, and the slides were washed twice with $2 \mathrm{X}$ SSC containing $0.1 \%$ SDS for $5 \mathrm{~min}$ at $42^{\circ} \mathrm{C}$, once with $0.1 \%$ SSC containing $0.1 \% \mathrm{SDS}$ for $1 \mathrm{~min}$ at room temperature, and finally with $0.1 \% \mathrm{SSC}$ for $1 \mathrm{~min}$ at room temperature. The slides were then dried by centrifugation at $650 \mathrm{rpm}$ for $5 \mathrm{~min}$. Hybridized arrays were scanned with a Scanarray lite (Packard Bioscience, Boston, MA) and analyzed by GenePix Pro 3.0 software (Axon Instruments, Union City, CA) to obtain a gene expression ratio (Cy-3 vs $\mathrm{Cy}-5)$. A typical false color image is depicted, showing red signals for stronger diseased sample hybridization, green signals for stronger control sample hybridization, and yellow signals for relatively equal transcript abundance.

Analysis of cDNA microarray data. Data analysis was performed using the GenePlex (Istech, Inc., Korea). Logged gene expression ratios from the fluorescent intensity of each spot were normalized by LOWESS (locally weighted scatter plot smoother) regression. Data and statistical significance of the differential expression were performed by computing a q-value for each gene (11).

\section{Results}

MA plots. To compare differential expression, microarray data was normalized with the lowest of the experiments repeated in triplicate. The normalized log ratios of varied genes in each experiment were used to analyze the relativity between two independent experiments. Relative changes were then calculated and were plotted on the basis of mean value intensities of each spot in three experiments (Fig. 1).

Gene expression profiles in APPsw-transgenic mice. Gene expression profiles of the brains from 18-month-old APPsw- transgenic mice were compared to those of 1-month-old $A P P s w$-transgenic mice using cDNA microarray. Of the 7616 genes, 6 genes in the 18 -month-old $A P P s w$-transgenic mouse brains were significantly up-regulated (Table IB) and 42 genes were down-regulated compared to those in the 1-month-old APPsw-transgenic mice (Table IA). The 6 genes with increased expression and the 42 genes with decreased expression include the proteins and enzymes related to cell growth, cell cycle, cell death, immune system, signal transduction, transcription, and stress.

Gene expression profiles in normal mice. Gene expression profiles of the brains from 18-month-old BDF1 mice were compared to those of 1-month-old BDF1 mice using cDNA microarray. Of the 7616 genes, 6 genes in the 18-month-old mouse brains were significantly up-regulated and 34 genes were down-regulated compared to those in the 1-monthold mice (Table IIA and B). The 40 genes include the proteins and enzymes related to cell growth, cell cycle, cell death, immune system, signal transduction, transcription, and stress.

\section{Discussion}

In this study, late-stage transgenic mice overexpressing APPsw and normal mice were used to address a hypothesis that genes for $\mathrm{AD}$ and aging modulate in a large scale compared to early-stage transgenic and normal mice. The approach of cDNA microarray has allowed us to offer critical insight that may have an impact on the complexity of $\mathrm{AD}$ and the aging process.

We identified that 6 genes from the brains of 18-monthold transgenic mice were significantly up-regulated and 42 genes were down-regulated compared to those in the brains of 1-month-old transgenic mice of the 7617 mouse cDNA clones (Twin Chip Mouse-7.4K). A total of 48 genes are involved in the areas of 7 categories relating to growth, cell cycle, apoptosis, signal transduction, transcription, immune system, and stress. These changes in gene expression resulted from the overexpression of NSE-controlled APPSw 
Table II. Gene profile in non-transgenic normal mice.

A. Down-regulated genes.

\begin{tabular}{lcc}
\hline Gene Symbol & Description & $\begin{array}{c}\text { GenBank } \\
\text { accession no. }\end{array}$ \\
\hline
\end{tabular}

\begin{tabular}{|c|c|c|c|}
\hline \multicolumn{4}{|l|}{ Apoptosis } \\
\hline Cradd & CASP2 and RIPK1 domain containing adaptor with death domain & AI426523 & -2.37 \\
\hline Cd51 & CD5 antigen-like & AI047839 & -2.32 \\
\hline Egln 3 & EGL nine homolog 3 (C. elegans) & AA717115 & -2.05 \\
\hline \multicolumn{4}{|l|}{ Cell cycle } \\
\hline $\mathrm{Cdc} 25 \mathrm{a}$ & cell division cycle 25 homolog A (S. cerevisiae) & AI848278 & -2.32 \\
\hline \multicolumn{4}{|c|}{ Cell growth and maintenance } \\
\hline $\operatorname{Mg} 29$ & mitsugumin 29 & AI427574 & -3.93 \\
\hline Sec15 & SEC15 homolog (S. cerevisiae) & AI429813 & -3.72 \\
\hline Col1a2 & procollagen, type I, $\alpha 2$ & AI841886 & -3.39 \\
\hline Col1a1 & procollagen, type I, $\alpha 1$ & AI425767 & -2.91 \\
\hline Hbb-bh1 & hemoglobin Z, B-like embryonic chain & AI385765 & -2.91 \\
\hline Lrp10 & low-density lipoprotein receptor-related protein 10 & AI448458 & -2.89 \\
\hline \multirow[t]{2}{*}{ Adamts2 } & a disintegrin-like and metalloprotease (reprolysin type) & W71229 & -2.67 \\
\hline & with thrombospondin type 1 motif, 2 & & \\
\hline $\mathrm{Mpz}$ & myelin protein zero & AA080181 & -2.66 \\
\hline Yes & Yamaguchi sarcoma viral (v-yes) oncogene homolog & AI323763 & -2.39 \\
\hline Col3a1 & procollagen, type III, $\alpha 1$ & AI842703 & -2.38 \\
\hline Ly75 & lymphocyte antigen 75 & AA867690 & -2.28 \\
\hline Csng & casein $\gamma$ & AI121961 & -2.17 \\
\hline Gsn & gelsolin & AI850094 & -2.15 \\
\hline Trappc3 & trafficking protein particle complex 3 & AI452141 & -2.11 \\
\hline Slc23a1 & solute carrier family 23 (nucleobase transporters), member 1 & AI428174 & -2.06 \\
\hline \multicolumn{4}{|c|}{ Immune response } \\
\hline Rag1 & recombination activating gene 1 & AA153443 & -3.38 \\
\hline \multicolumn{4}{|c|}{ Response to stress } \\
\hline Eif2ak3 & eukaryotic translation initiation factor $2 \alpha$ kinase 3 & AI427929 & -3.53 \\
\hline Orm1 & orosomucoid 1 & AI1 17779 & -2.92 \\
\hline Tacc3 & transforming, acidic coiled-coil containing protein 3 & AI429136 & -2.02 \\
\hline \multicolumn{4}{|c|}{ Signal transduction } \\
\hline Catnal1 & catenin $\alpha$-like 1 & AW319897 & -5.08 \\
\hline Pcp2 & Purkinje cell protein 2 (L7) & AI843793 & -4.53 \\
\hline Tyk2 & tyrosine kinase 2 & AI452085 & -3.97 \\
\hline Gna13 & guanine nucleotide binding protein, $\alpha 13$ & AI426467 & -3.34 \\
\hline $\mathrm{Mc} 2 \mathrm{r}$ & melanocortin 2 receptor & AI153955 & -2.86 \\
\hline Car8 & carbonic anhydrase 8 & AI838156 & -2.85 \\
\hline Hrh3 & histamine receptor $\mathrm{H} 3$ & AI452091 & -2.57 \\
\hline Adrb2 & adrenergic receptor, $\beta 2$ & AA111732 & -2.37 \\
\hline \multicolumn{4}{|c|}{ Transcription } \\
\hline Harp & harmonin interacting ankyrin repeat containing protein & AI452087 & -3.86 \\
\hline Gata3 & GATA binding protein 3 & AI428208 & -2.89 \\
\hline Asxl1 & additional sex combs like 1 (Drosophila) & AI837616 & -2.14 \\
\hline
\end{tabular}

in 1- and 18-month-old transgenic mice. The genes associated with $\mathrm{AD}$ are in the area of 7 categories. First, genetic mutations in genes lead to the risk of AD. The risk of AD was increased by a mutation in the brain-specific Abca2 gene, which is known to participate in cholesterol and phospholipid transport (12). Also, a mutation in the Chrna4 gene coding for the most widely distributed nicotinic receptor subtype $\mathrm{II}$ is associated with the late-onset of $\mathrm{AD}$ 
Table II. Continued.

B. Up-regulated genes.

\begin{tabular}{|c|c|c|c|}
\hline Gene Symbol & Description & $\begin{array}{c}\text { GenBank } \\
\text { accession no. }\end{array}$ & Fold change \\
\hline \multicolumn{4}{|l|}{ Cell cycle } \\
\hline Cetn2 & centrin 2 & AI326150 & 2.01 \\
\hline Gmnn & geminin & AI504205 & 2.82 \\
\hline \multicolumn{4}{|c|}{ Cell growth and maintenance } \\
\hline Slc16a1 & solute carrier family 16 (monocarboxylic acid transporters), member 1 & AI427128 & 5.46 \\
\hline \multicolumn{4}{|c|}{ Signal transduction } \\
\hline Tlr4 & toll-like receptor 4 & AA175249 & 2.15 \\
\hline Gngt2 & $\begin{array}{l}\text { guanine nucleotide binding protein (G protein), } \gamma \text { transducing activity } \\
\text { polypeptide } 2\end{array}$ & AI154009 & 4.39 \\
\hline \multicolumn{4}{|l|}{ Transcription } \\
\hline Cops 2 & $\begin{array}{l}\text { COP9 (constitutive photomorphogenic) homolog, subunit } 2 \\
\text { (Arabidopsis thaliana) }\end{array}$ & AI842912 & 2.03 \\
\hline
\end{tabular}

(5). In gelsolin the mutation corresponds to codon 187, and the mutated gene is expressed in the amyloid fibril at residue 15 (13). Moreover, a deletion in the GSTT1 gene enhanced susceptibility to AD (14). A polymorphism in the tumor necrosis factor $(T C F)$, in association with apolipoprotein $\mathrm{E}$ (APOE) was reported to increase the AD risk (15). Secondly, changes in the concentration or activity of genes have been shown to result in AD. Loss, late-developed, granular degeneration, and breakdown in myelin lead to the pathogenesis of AD $(16-18,24)$. It was demonstrated that reduced sensitivity/density or activation in adrenergic receptor 2 (Adrb2) contributes to the stress in caregivers of $\mathrm{AD}$ and the neuronal apoptosis in $\mathrm{AD}(20,21)$. In carbonic anhydrase, dysfunction impairs cognition and is associated with AD (22). The protein level of $\gamma$-aminobutylic acid (GABA) receptor subunits-1 or -5 in the hippocampus was increased in displaying the severity of AD neuropathology $(19,21)$. Modulation of the mitogen-activated protein kinase (MAPK) kinase kinase, a member of the MAPK superfamily, may be crucial in the neuropathology of AD, since MAPK activation is a regulator of the formation of the plaques leading to AD (23). There are three enzymes in retinoic acid-induced 3 (Rai3), i.e. phospholipase A2, phospholipase C, and phospholipase D. Of the Rai3 enzymes, downstream transcriptional regulation of phospholipase A2-mediated signal transduction is involved in AD (24). When tissues from AD brains were immunostained with anti-spectrin 32 , B-amyloid plaques were significantly stained in the cortical parenchyma (25). A decrease in glutathione S-transferase (GST) activity was observed in all areas of AD (26). In addition, syntaxin 1A was identified as a novel binding protein for presenilin 1 (27). Other genes listed may also be associated with $\mathrm{AD}$ pathogenesis, but it is unknown.

Six genes from the brains of 18-month-old mice were significantly up-regulated and 34 genes were down-regulated compared to those in the brains of 1-month-old mice of the 7617 mouse cDNA clones (Twin Chip Mouse-7.4K). A total of 40 genes are involved in the areas of 7 categories relating to growth, cell cycle, apoptosis, signal transduction, transcription, immune system, and stress. There are genes associated with the aging brain in some of the areas of the 7 categories. Firstly, genetic mutations in genes lead to disease. It was demonstrated that mutations of the Harp gene are responsible for deafness in the Jackson shaker 2 (js) mutant mice and in humans (28). The variation in the histamine H3 receptor (HRH3) in patients with Shy-Drager syndrome is also related to the etiology of the illness due to altered norepinephrine release (29). Moreover, a mutation in the $\mathrm{Mpz}$ genes has been found in patients with congenital hypomyelinating neuropathy (CHN), and GNGT2 is the site of a mutation responsible for inherited retinal degeneration $(30,31)$. In addition, mice deficient in TYK2 developed Abelson-induced B lymphoid leukemia lymphoma, and in $\mathrm{Rag}^{1 /-}$ mutants, stage-specific increases were observed in the proliferation profile of fetal thymocyte compared to wildtype fetal thymocyte $(32,33)$. Secondly, the identification of specific genes provides further insight into the understanding of the features of cell cycle, cell proliferation, and apoptosis. Human geminin (Gmnn) ensures basal levels of CDT1 during the $\mathrm{S}$ phase and its accumulation during mitosis (34). It was also demonstrated that centrin 2 (Cetn2) gene coding for the calcium-binding protein localizes in the region immediately surrounding the centrioles in the centrosome, which plays a diverse role throughout the cellular mitotic cell and in postmitotic cells (35). Cradd plays an important role in regulating apoptosis in mammalian cells, and EGLN3, a family of Egl-Nine (EGLN), is the human orthologue of rat Sm-20 that is a novel family of prolyl hydroxylase, which include a growth-responsive and cell-death-related protein (Sm-20) in mammals (36,37). Moreover, Mitsugumin 29 (MG29) serves an essential role in muscle $\mathrm{Ca}^{2+}$ signaling, which has been shown to regulate the process of cell proliferation and apoptosis (38). In addition, human cytoplasmic gelsolin inhibits $A B$ peptide-induced cell death 
of neuronally differentiated rat PC-12 cells (39). In the $C d c 25 A$ gene, its expression displayed increased immunoreactivity with the mitotic phosphoepitope-specific antibody and was correlated with proliferating cell nuclear antigen labeling index $(40,41)$. Thirdly, the identified genes are related to embryogenesis, differentiation, and development. It has been demonstrated that Asxl1 is implicated in embryogenesis and carcinogenesis due to the transcriptional regulation of target genes through histone modification and chromatin remodeling, and Pcp2, known as L7, plays an important role in controlling the development and/or motor control function of Purkinje cells $(42,43)$. Also, an up-regulation of TACC occurs during the early differentiation of PC12 cells into neurons and in embryonic, postnatally developing, and adult mouse tissue $(44,45)$. In addition, Ly75 (DEC-205) transcripts were significantly increased upon differentiation (46). Fourthly, of the identified genes, the levels of gene expression lead to altered phenotypes. Expression of Toll-like receptor (TLR) 4, a member of interleukin-1 receptor (IL-1R), was decreased in the brain and is critically required for sustained inflammation on CNS resident cells in the brain after systemic administration of LPS $(47,48)$. Moreover, a high level of Car8 expression appeared in the pyramidal and granular cells of the hippocampus, and expression of Slc23al is required for transporting vitamin C into the brain $(49,50)$. Recently, the expression of ADAMTS protein was shown to have a role in a variety of diseases including Alzheimer's disease (51). In addition, yeast sec15 expressed synaptotagmin II, which is a neurally expressed protein, thought to be involved in neurotransmitter release from neurons (52). Other genes listed may also be associated with the aging process, but it is unknown. Adrb2 was expressed in rat microglial cells (53).

In conclusion, we provide evidence that the approach of cDNA microarray leads to 48 or 40 differentially regulated genes in transgenic and normal mice upon APPsw overexpression. In the future, it will be necessary to study the function of differentially expressed gene, which are targets for developing drugs, using pharmacoproteomics.

\section{Acknowledgements}

We thank both Sun M. Choi and Mi K. Jang, animal technicians directing the animal facility at the Team of Laboratory Animal Resources. This research was supported by grants to Dr Yong K. Kim from the Korea Health $21 \mathrm{R} \& \mathrm{D}$ Project, Ministry of Health and Welfare, Republic of Korea (A040042) and the Korea FDA.

\section{References}

1. Selkoe DJ: Translating cell biology into therapeutic advances in Alzheimer's Disease. Nature 399: A23-A31, 1999.

2. Yamazaki T, Koo EH and Selkoe DJ: Trafficking of cell-surface amyloid beta-protein precursor II. Endocytosis, recycling and lysosomal targeting detected by immunolocalization. J Cell Sci 109: 999-1008, 1996.

3. Ginsberg SD, Hemby SE, Lee VM, Eberwine JH and Trojanowski JQ: Expression profile of transcript in Alzheimer's disease tangle-bearing CA1 neurons. Ann Neurol 48: 77-87, 2000.

4. Pasinetti GM and Ho L: From cDNA microarrays to highthroughput proteomics: Implications in the search for preventive initiatives to slow the clinical progression of Alzheimer's disease dementia. Restor Neurol Neurosci 18: 137-142, 2001.
5. Cook LJ, Ho LW, Taylor AE, Brayne C, Evans JG, Xuereb J, Cairns NJ, Pritchard A, Lemmon H, Mann D, St Clair D, Turic D, Hollingworth P, Moore PJ, Jehu L, Archer N, Walter S, Foy C, Edmondson A, Powell J, Lovestone S, Owen MJ, Williams J, Lendon $\mathrm{C}$ and Rubinstein DC: Candidate gene association studies of the alpha 4 (CHRNA4) and beta 2 (CHRNB2) neuronal nicotinic acetylcholine receptor subunit genes in Alzheimer's disease. Neurosci Lett 358: 142-146, 2004.

6. Dickey CA, Loring JF, Montgomery J, Gordon MN, Eastman PS and Morgan D: Selectively reduced expression of synaptic plasticity-related genes in amyloid precursor protein+presenilin1 transgenic mice. J Neurosci 23: 5219-5226, 2003.

7. Hwang DY, Cho JS, Lee SH, Chae KR, Lim HJ, Min SH, Seo SJ, Song YS, Song CW, Paik SG, Sheen YY and Kim YK: Aberrant expressions of pathogenic phenotype in Alzheimer's diseased transgenic mice carrying NSE-controlled APPsw. Exp Neurol 186: 20-32, 2004

8. Jee SW, Cho JS, Oh JH, Shim SB, Hwang DY, Lee SH, Song YS, Lee $\mathrm{SH}$ and Kim Y: cDNA microarray-based analysis of differentially expressed genes in transgenic brains expressing NSE-controlled APPsw. Int J Mol Med 16: 547-552, 2005.

9. Kinsbury GA and Junghans RP: Screening of phage display immunoglobulin libraries anti-M13 ELISA and whole phage PCR. Nucleic Acids Res 23: 2563-2564, 1995.

10. Hong SH, Nah HY, Lee JY, Gye MC, Kim CH and Kim MK: Analysis of estrogen-regulated genes in mouse uterus using cDNA microarray and laser capture microdissection. J Endocrinol 181: 157-167, 2004.

11. Tusher VG, Tibshrani $\mathrm{R}$ and $\mathrm{Chu}$ G: Significance analysis of microarrays applied to the ionizing radiation response. Proc Natl Acad Sci USA 98: 5116-5121, 2001

12. Mace S, Cousin E, Ricard S, Genin E, Spanakis E, Lafargue-Soubigou C, Genin B, Fourned R, Roche S, Haussy G, Massey F, Soubigou S, Brefort G, Benoit P, Brice A, Campion D, Holls M, Pradier L, Benavides J and Delenze JF: ABCA2 is a strong genetic risk factor for early-onset Alzheimer's disease. Neurobiol Dis 18: 1119-1125, 2005.

13. Haltia M, Ghiso J, Wisniewski T, Kiuru S, Miller D and Frangione B: Gelsolin variant and beta-amyloid co-occur in a case of Alzheimer's with Lewy bodies. Neurobiol Aging 12: 313-316, 1991.

14. Stroombergen MC and Waring RH: Determination of glutathione S-transferase mu and theta polymorphism in neurological disease. Hum Exp Toxicol 18: 141-145, 1999.

15. Laws SM, Perneczky R, Wagenpfeil S, Muller U, Forstl H, Martins RN, Kurz A and Riemeschneider M: TNF polymorphism in Alzheimer's disease and functional implications on CSF B-amyloid levels. Hum Mutat 26: 29-35, 2005.

16. Bartzokis G: Age-related myelin breakdown: a developmental model of cognitive decline and Alzheimer's disease. Neurobiol Aging 25: 5-18, 2004.

17. Bartzokis G, Lu PH and Mintz J: Quantifying age-related myelin breakdown with MRI: novel therapeutic targets for preventing cognitive decline and Alzheimer's disease. J Alzheimer Dis 6: S53-S59, 2004.

18. Tian J, Shi J, Bailey K and Mann DM: Relationship between arteriosclerosis, cerebral amyloid angiopathy and myelin loss from cerebral cortical white matter in Alzheimer's disease. Neuropathol Appl Neurobiol 30: 46-56, 2004.

19. Mizukami K, Ikonomovic MD, Grayson DR, Sheffield R and Amstrong DM: Immunohistochemical study of GABAA receptor 1 subunit in the hippocampal formation of aged brains with Alzheimer-related neuropathologic changes. Brain Res 799: 148-155, 1998.

20. Mills PJ, Adler KA, Dimsdale JE, Perez CJ, Ziegler MG, Ancoli-Israel S, Patterson TL and Grant I: Vulnerable caregivers of Alzheimer disease patients have a deficit in 2adrenergic receptor sensitivity and density. Am J Geriatr Psychiatry 12: 281-286, 2004.

21. Rissman RA, Mishizen-Eberz AJ, Carter TL, Wolfe BB, De Blas AL, Miralles CP, Ikonomovic MD and Amstrong DM: Biochemical analysis of $\mathrm{GABA}(\mathrm{A})$ receptor subunits alpha 1 , alpha 5 , beta 1 , beta 2 in the hippocampus of patients with Alzheimer's disease neuropathology. Neuroscience 120: 695-704, 2003.

22. Sun MK and Alkon DL: Carbonic anhydrase gating of attention: memory therapy and enhancement. Trends Pharmacol Sci 23: 83-89, 2002.

23. Wang LH, Besirli CG and Johnson EM Jr: Mixed lineage kinases: a target for the prevention of neurodegeneration. Annu Rev Pharmacol Toxicol 44: 451-474, 2004. 
24. Farooqui AA, Antony P, Ong WY, Hprrocks LA and Freysz L: Retinoic acid mediated phospholipase A2 signaling in the nucleus. Brain Res Rev 45: 179-195, 2004.

25. Sihag RK and Cataldo AM: Brain beta-spectrin is a component of senile plaques in Alzhemer's disease. Brain Res 743: 249-257, 1996.

26. Lovell MA, Xie C and Markesbery WR: Decreased glutathione transferase activity in brain and ventricular fluids in Alzheimer's disease. Neurology 51: 1562-1566, 1998.

27. Smith SK, Anderson HA, Yu G, Robertson AG, Allen SJ, Tyler SJ, Naylor RL, Mason G, Wicock GW, Roche PA, Frased PE and Dawbarn D: Identification of syntax $1 \mathrm{~A}$ as a binding protein for presenilin-1. Brain Res Mol Brain Res 78: 100-107, 2000.

28. Johnston AM, Naselli G, Niwa H, Brodnick T, Harrison LC and Gonez LJ: Harp (harmonin-interacting, ankyrin repeatcontaining protein), a novel protein that interacts with harmonin in epithelial tissues. Gene Cells 9: 967-982, 2004.

29. Wiedemann P, Bonisch H, Oerters F and Bruss M: Structure of the human histamine $\mathrm{H} 3$ receptor gene (HRH3) and identification of naturally occurring variations. J Neural Transm 109: 443-453, 2002.

30. Kochanski A, Drac H, Kabzinska D, Ryniewicz-Marcinska K, Nowakowski A and Hausmanowa-Petrusewicz I: A novel MPZ gene mutation in congenital neuropathy with hypomyelination. Neurology 62: 2122-2123, 2004.

31. Gao YQ, Danciger M, Akhmedov NB, Zhao DY, Heckenlively JR, Fishman GA, Weleber RG, Jacobson SG and Farber DB: Exon screening of the genes encoding the beta- and gamma-subunits of cone transduction in patients with inherited retinal disease. Mol Vis 4: 16, 1998.

32. Stoiber D, Kocacic B, Schuster C, Schellack C, Karaghiosoff M, Kreibich R, Weisz E, Artwohl M, Kline OC, Muller M, Baumgartner-Parzer S, Ghysdael J, Freissmuth M and Sexl V: TYK2 is a key regulator of the surveillance of B lymphoid tumors. J Clin Invest 114: 1650-1658, 2004.

33. Su DM and Manley NR: Stage-specific changes in fetal thymocyte proliferation during the CD4-8 to CD4+8+ transition in wild type, Rag1-/-, and Hoxa3, Pax 1 mutant mice. BMC Immunol 3: 12, 2002.

34. Ballabeni A, Melixetian M, Zamponi R, Masiero L, Marinoni F and Helin K: Human geminin promotes pre-RC formation and DNA replication by stabilizing CDT1 in mitosis. EMBO J 23: 3122-3132, 2004.

35. Hart PE, Poynter GM, Whitehead CM, Orth JD, Glantz JN, Busby RC, Barrett SL and Salisbury JL: Characterization of the X-liked murine centrin Cetn2 gene. Gene 264: 205-213, 2001.

36. Ahmad M, Srinivasula SM, Wang L, Talanian RV, Litwack G and Fernandes-Alnemri ES: CRADD, a novel human apoptotic adaptor molecule for caspase-2, and FasL/tumor necrosis factor receptor-interacting protein RIP. Cancer Res 57: 615-619, 1997.

37. Freeman RS, Hasbani DM, Lipscomb EA, Straub JA and Xie L: SM-20, EGL-9, and EGLN family of hypoxia-inducible factor prolyl hydroxylases. Mol Cell 16: 1-12, 2003.

38. Pan Z, Hirata Y, Nagalaj RY, Zhao J, Nishi M, Hayek SM, Bhat MB, Takeshima M and Ma J: Co-expression of MG29 and ryanodine receptor leads to apoptotic cell death: effect mediated by intracellular Ca2+ release. J Biol Chem 279: 19387-19390, 2004.
39. Qiao H, Koya RC, Nakagawa K, Tanaka H, Fugita H, Takimoto M and Kuzumaki N: Inhibition of Alzheimer's amyloid-beta peptide-induced reduction of mitochondrial membrane potential and neurotoxicity by gelsolin. Neurobiol Aging 26: 849-855, 2005.

40. Ding XL, Husseman J, Tomashevski A, Nochlin D, Jin LW and Vincent I: The cell cycle Cdc25A tyrosine phosphatase is activated in degenerating postmitotic neurons in Alzheimer's disease. Am J Pathol 157: 1983-1990, 2000.

41. Xu X, Yamamoto H, Sakon M, Yasui M, Ngan CY, Fukunaga H, Morita T, Ogawa M, Nagano H, Nakamori S, Sekimoto M, Matsuura $\mathrm{N}$ and Monden M: Overexpression of CDC25A phosphotase is associated with hypergrowth activity and poor prognosis of human hepatocellular carcinomas. Clin Cancer Res 9: 1764-1772, 2003

42. Katoh $\mathrm{M}$ and Katoh $\mathrm{M}$ : Identification and characterization of ASXL2 in silico. Int J Oncol 23: 845-850, 2003.

43. Zhang X, Zhang H and Oherdick J: Conservation of the developmentally regulated dendritic localization of a Purkinje cell-specific mRNA that encodes a G-protein modulator: comparison of rodent and human Pep2(L7) gene structure and expression. Brain Res Mol Brain Res 105: 1-10, 2002.

44. Sadec CM, Pelto-Huikko M, Tujague M, Steffensen KR, Wennerholm $M$ and Gustafsson JA: TACC 3 expression is tightly regulated during early differentiation. Gene Exp Patterns 3: 203-211, 2003.

45. Aitola M, Sadec CM, Gustafsson JA and Pelto-Huito-Huikko M: Aint/Tacc3 is highly expressed in proliferating mouse tissues during development, spermatogenesis, and oogenesis. J Histochem Cytochem 51: 455-469, 2003.

46. Kato M, Neil TK, Clark GL, Morris CM, Sorg RV and Hart DN: cDNA cloning of human DEC-205, a putative antigen-uptake receptor on dendritic cells. Immunogenetics 47: 442-450, 1998.

47. Matsumura T, Ito A, Takii T, Hayashi H and Onozaki K: Endotoxin and cytokine regulation of toll-like receptor (TLR)2 and TLR4 gene expression in murine liver and hepatocytes. J Interferon Cytokine Res 20: 915-921, 2000.

48. Chakravarty S and Herkenham M: Toll-like receptor 4 on nonhematopoietic cells sustains CNS inflammation during endotoxemia, independent of systemic cytokines. J Neurosci 25: 1788-1796, 2005 .

49. Lakkis MM, Bergenhem NC, O'Shea KS and Tashian RE: Expression of the acatalytic carbonic anhydrase VIII gene, Car8, during mouse embryonic development. J Histochem Cytochem 29: 135-141, 1997.

50. Sotirion S, Gispert S, Cheng J, Wang Y, Chen A, Hoogstraten-Miller S, Miller GF, Kwon O, Levine M, Guttentag SH and Nussbaum RL: Ascrobic-acid trasporter Sle23a1 is essential for vitamin $\mathrm{C}$ transport into the brain and for perinatal survival. Nat Med 8: 514-517, 2002.

51. Nicholson AC, Malik SB, Logsdon JM Jr and van Meir EG: Functional evolution of ADAMTS genes: evidence from analyses of phylogeny and gene organization. BMC Evol Biol 5: 11,2005 .

52. Damer CK and Creutz CE: Synaptotagmin II expression partially rescues the growth defect of the yeast sec 15 secretory mutant. Biol Cell 88: 55-63, 1996.

53. Tanaka KF, Kashima H, Suzuki H, Ono K and Sawada M: Existence of functional beta1-and beta2-adrenergic receptors on microglia. J Neurosci Res 70: 232-237, 2002. 